\title{
Congenital urinary tract obstruction: defining markers of developmental kidney injury
}

\author{
Peter Trnka ${ }^{1,2}$, Michael J. Hiatt ${ }^{3,4}$, Alice F. Tarantal ${ }^{5-8}$ and Douglas G. Matsel| ${ }^{3,4}$
}

Congenital urinary tract obstruction (diagnosed antenatally by ultrasound screening) is one of the main causes of end-stage kidney disease in children. The extent of kidney injury in early gestation and the resultant abnormality in kidney development determine fetal outcome and postnatal renal function. Unfortunately, the current approach to diagnostic evaluation of the severity of injury has inherently poor diagnostic and prognostic value because it is based on the assessment of fetal tubular function from fetal urine samples rather than on estimates of the dysplastic changes in the injured developing kidney. To improve the outcome in children with congenital urinary tract obstruction, new biomarkers reflecting these structural changes are needed. Genomic and proteomic techniques that have emerged in the past decade can help identify the key genes and proteins from biological fluids, including amniotic fluid, that might reflect the extent of injury to the developing kidney.

ongenital abnormalities are detected in $1-2 \%$ of pregnancies, with involvement of the urinary tract being seen in $\sim 20 \%$ of these cases (1). Registries and databases in Europe (2), North and Central America (3), and Australia and New Zealand (4) show that hypoplasia/dysplasia of the kidney, often associated with obstructive nephropathy, is the leading cause of end-stage kidney disease in childhood.

The outcome for patients with severe obstructive nephropathy has not improved significantly over the past two decades despite advances in antenatal diagnosis and therapeutic interventions $(5,6)$. The currently available diagnostic tests lack sufficient clinical sensitivity and specificity because they reflect the functional changes in the immature kidney (pathophysiology) rather than the degree of structural damage and potential for postnatal deficit (pathogenesis).

In this article, we review current diagnostic and therapeutic approaches to human fetal obstructive nephropathy, discuss the advantages and disadvantages of the available tests, and outline the potential for new diagnostic approaches to this condition.

\section{ESTIMATES OF ABNORMAL FETAL KIDNEY STRUCTURE}

Most cases of congenital urinary tract obstruction are identified during the second-trimester ultrasound screening. A distended thick-walled bladder, hydroureters, and bilateral hydronephrosis in the fetus imply lower-urinary-tract obstruction (Figure 1a) (7). Increased echogenicity of the kidneys, a poorly defined corticomedullary border, and cystic parenchymal changes suggest renal dysplasia (Figure 1b) (8). When associated with severe oligohydramnios in early pregnancy, these changes carry a poor prognosis and are associated with a $>90 \%$ perinatal mortality (9).

Studies analyzing the predictive value of antenatal ultrasound screening have yielded conflicting results. Anumba et al. (10) reported that echogenic and/or cystic changes of fetal kidneys have a predictive value of $59 \%$ in detecting dysplasia histologically or chronic kidney disease on postnatal follow-up. The predictive value of normal parenchyma (on prenatal ultrasound) in detecting the absence of dysplasia or normal renal function was 56\%. Detailed ultrasound examination of the urinary tract, particularly when performed by an experienced operator, yields a higher accuracy of diagnosis of congenital urinary tract obstruction (11). Fetal magnetic resonance imaging can provide a more detailed assessment of the fetal urinary tract $(12,13)$, but predictive values of magnetic resonance imaging for congenital urinary tract obstruction are difficult to ascertain, given the selective use of this method and the small numbers of published cases.

With regard to fetal kidney biopsy, there has been a poor success rate in obtaining renal tissue from a compromised kidney. This, combined with the fact that additional information is likely to be minimal, precludes wider use of this invasive procedure (14).

Consequently, although the currently available imaging modalities may provide an accurate diagnosis of congenital renal disorders, they are poor predictors of postnatal function, particularly as regards intermediate forms of dysplasia.

\section{ESTIMATES OF ABNORMAL FETAL KIDNEY FUNCTION}

Measurement of fetal glomerular filtration rate (GFR) would be an ideal determinant of renal function, a good surrogate for the severity of dysplasia, and an efficient predictor of postnatal function; however, there are no normative data for this parameter in uncomplicated pregnancies (15), and it is challenging to determine GFR accurately in the fetus. $\beta_{2}$-microglobulin, the light

'Department of Paediatrics and Child Health, University of Queensland, Brisbane, Australia; ${ }^{2}$ Queensland Child and Adolescent Renal Service, Royal Children's Hospital, Brisbane, Australia; ${ }^{3}$ Department of Pediatrics and Division of Nephrology, BC Children's Hospital, Vancouver, British Columbia, Canada; ${ }^{4}$ Child and Family Research Institute, Vancouver, British Columbia, Canada; ${ }^{5}$ California National Primate Center, University of California, Davis, Davis, California; ${ }^{6}$ Department of Pediatrics, University of California, Davis, Davis, California; ${ }^{7}$ Department of Cell Biology, University of California, Davis, Davis, California; ${ }^{8}$ Department of Human Anatomy, University of California, Davis, Davis, California. Correspondence: Douglas G. Matsell (dmatsell@cw.bc.ca) 

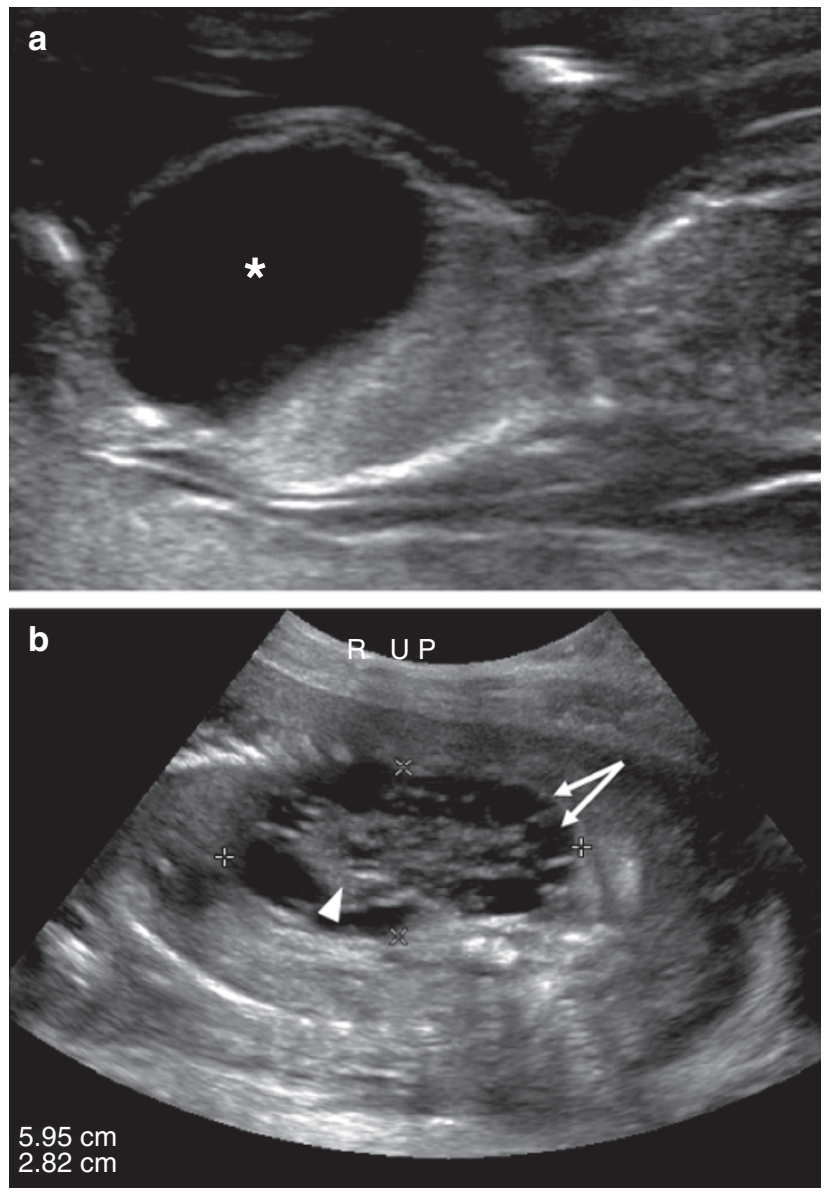

Figure 1. Antenatal ultrasound of congenital urinary tract obstruction. (a) Ultrasound image of a 12-wk-gestation human fetus with bladder outlet obstruction caused by posterior urethral valves (PUVs), showing enlarged bladder (asterisk $(*)$ ). (b) Ultrasound image of an enlarged, echogenic 21-wk-gestation kidney with multiple parenchymal cysts (arrows) and poorly defined corticomedullary border (arrowhead) in a human fetus with PUVs (courtesy of Ken Lim, British Columbia Women's Hospital, Vancouver, Canada). R, right kidney; UP, anterior view.

chain of the class I major histocompatibility antigens, has been used as an indirect measure of fetal GFR. It is advantageous to use this antigen for GFR estimation because of its constant production by the fetus, its inability to cross the placental barrier, and its free filtration at the glomerulus (16-18). Fetuses with urinary tract obstruction had higher serum $\beta_{2}$-microglobulin levels than those without obstruction (Figure 2a, ref. 19). A fetal serum $\beta 2$-microglobulin cut-off value of $5.6 \mathrm{mg} / \mathrm{l}$ had a sensitivity of $80 \%$, a specificity of $98.6 \%$, a positive predictive value of $88.9 \%$, and a negative predictive value of $97.1 \%$ for postnatal renal failure (16). Filtered $\beta 2$-microglobulin undergoes $99.9 \%$ degradation by proximal tubular cells. Levels $<6 \mathrm{mg} / \mathrm{l}$ in urine are considered "normal" in fetuses with congenital urinary tract obstruction (20), whereas levels $>13 \mathrm{mg} / \mathrm{l}$, reflecting tubular damage, were invariably associated with perinatal death (21). However, the usefulness of $\beta 2$-microglobulin as a marker is limited because (i) there is a lack of normative data; (ii) the available studies were carried out in small numbers of patients; (iii) measurements reported in different studies were made at different a

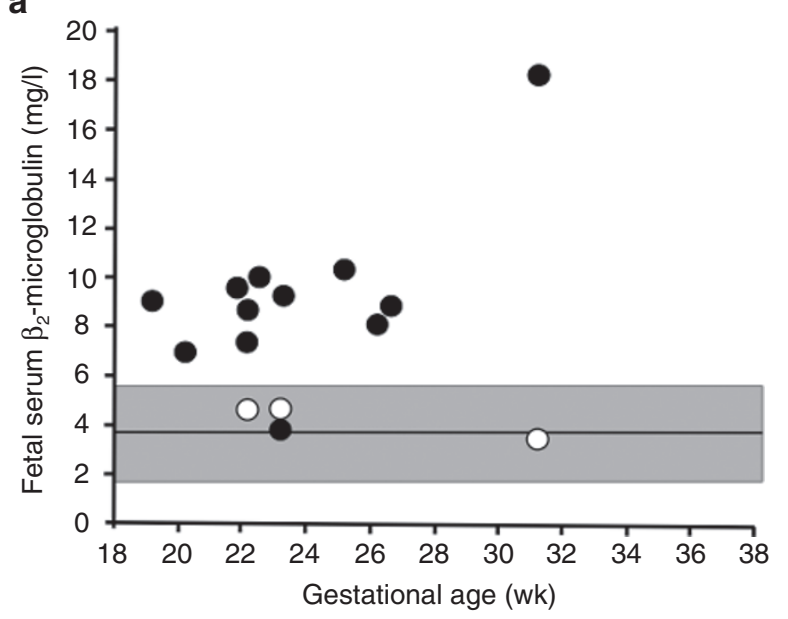

b

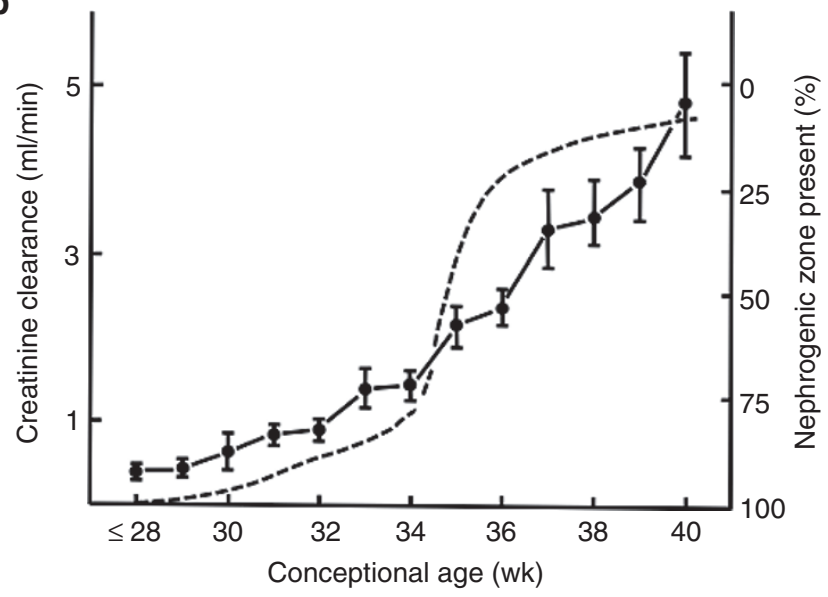

Figure 2. Developmental changes in fetal serum $\beta_{2}$-microglobulin and GFR, and their relationship to nephrogenesis. (a) Fetal serum $\beta_{2}-$ microglobulin levels in 15 human fetuses with urinary tract obstruction as compared with the reference range (shaded area) of levels from 73 fetuses without urinary tract obstruction (filled circles: fetuses with renal damage, open circles: fetuses without renal damage). Reference range represents the mean value \pm 2 SD of serum $\beta_{2}$-microglobulin, with the upper limit of $5.6 \mathrm{mg} / \mathrm{l}$. Values above the upper limit of the reference range were recorded in 11 of the 12 fetuses with renal damage. Adapted from ref. 19, with permission from John Wiley \& Sons. (b) The pattern of change in GFR, measured by validated creatinine clearance (solid line) and persistence of the nephrogenic zone in the renal cortex (dotted line) in relation to the conceptional age of the human neonate. Data obtained from samples from 205 neonates; $N$ ranging from 7 to 26 in groups at various gestational ages. Adapted from ref. 28 with permission. GFR, glomerular filtration rate.

stages of gestation; and (iv) the studies show variable measures of outcome. In addition, fetal blood sampling carries the risks of bleeding, amniotic fluid leak, infection, and fetal death.

In addition to GFR, urinary analytes have also been used in the antenatal evaluation of kidney function and as predictors of postnatal outcome. Antenatal estimates are dynamic and are dependent on gestational age and, as with glomerular filtration, tubular function also undergoes significant changes during fetal maturation. During early development, the urinary ultrafiltrate is minimally modified by its passage through the nephron. With maturation, the tubules and collecting ducts become more efficient in reabsorption of water and electrolytes. Glick et al. (22) 
reported findings of normal levels of fetal urinary electrolytes and correlated these values with autopsy and biopsy findings, as well as clinical outcomes, in 20 fetuses with bladder outlet obstruction. A fetal urine sodium $<100 \mathrm{mEq} / \mathrm{l}$, chloride $<90$ $\mathrm{mEq} / \mathrm{l}$, and urine osmolality $>210 \mathrm{mEq} / \mathrm{l}$ at a mean gestational age of $23.8 \mathrm{wk}$ predicted "good outcome," reflected as the presence of nondysplastic kidneys at autopsy or biopsy, or normal renal and pulmonary function at birth. A recent comprehensive, systematic review of the literature on the accuracy of fetal urine analysis as a predictor of postnatal renal function in cases of congenital lower-urinary-tract obstruction revealed that there is currently no individual analyte or threshold with significant clinical accuracy (23).The thresholds of the most widely investigated measures (sodium, chloride, calcium, osmolality, and $\beta_{2}$ microglobulin) varied widely among the studies, and not all the studies correlated these thresholds with gestational age.

\section{ANTENATAL INTERVENTION}

The aim of antenatal intervention in lower-urinary-tract obstruction is to relieve the obstruction in fetuses that would benefit from such shunting (24). In most cases, these therapeutic decisions, which also include decisions involving termination of pregnancy, are based on studies of fetal urine and amniotic fluid, as outlined earlier in the paper. A large meta-analysis studied the outcomes of pregnancies complicated by urinary tract obstruction and oligohydramnios in which vesico-amniotic shunting was performed. Not surprisingly, given the inherent drawbacks of the selection criteria, the analysis reports $47 \%$ perinatal survival rate after successful shunting, with $40 \%$ of the survivors developing end-stage renal disease on follow-up (5). Similarly, long-term outcome studies in these patients show a high prevalence of bladder dysfunction requiring regular catheterization or placement of a vesicostomy, as well as urinary tract infections. There was also a tendency to develop asthma and recurrent respiratory infections because of pulmonary hypoplasia (25). Therefore, urinary diversion in the fetus has not resulted in the anticipated improvement in outcomes in pregnancies complicated by severe congenital urinary tract obstruction.

\section{DEVELOPMENT OF GLOMERULAR AND TUBULAR FUNCTION}

Clearly, the lack of accurate predictors of postnatal outcome and the difficulty in selecting fetuses that might benefit from intervention are important reasons for the poor outcomes in fetuses with congenital urinary tract obstruction. We suggest that the development of more robust clinical outcome predictors calls for a reconsideration of fetal kidney physiology.

Kidney function in the fetus is not sufficient to balance all the metabolic requirements of growth, nor is it necessary, given the interposition of the placenta and maternal-fetal membranes. Nevertheless, the contribution of fetal kidneys to fluid and electrolyte balance gradually increases as gestation progresses, eventually supplanting the contribution of the placenta at the time of birth. In humans, glomerular filtration begins shortly after 9 wk of gestation, which is when the first functional glomeruli appear (26). With time, up to $34 \mathrm{wk}$ of gestation, the GFR shows a slow linear increase, reflecting the development of new nephrons. Thereafter the rate increases rapidly with the completion of nephrogenesis (27), renal blood redistribution, and the engagement of younger cortical nephrons (Figure $\mathbf{2 b}$, ref. 28) (29). Fetal GFR increases in proportion to the body mass of the fetus (30). With the increase in cardiac output and growth of the renal vascular bed during gestation, renal blood flow also increases (31). The hemodynamic evolution of the fetal kidney is characterized by a shift from a low-flow, highresistance organ, with most of the blood flow supplying the inner cortex, to a high-flow, low-resistance organ, with most of the blood flow supplying the outer cortex (32).

Although the details of fetal kidney physiology are well defined, the clinical evaluation of fetal GFR remains a challenging exercise with elusive outcomes. A number of surrogates have been proposed. Given that GFR increases with fetal weight (Figure 3a) and that urine output increases with advancing gestation (Figure $3 \mathbf{b}$ ), fetal urinary flow rates have been used as a marker of fetal GFR $(33,34)$. However, as in the postnatal kidney, urine output does not correlate well with absolute GFR. Glomerular number, which would also presumably reflect fetal kidney function, is also proportional to fetal weight. In fact, the increase in glomerular number, GFR, and fetal urine flow correlate closely with the increase in kidney mass, and it is therefore reasonable to assume that the main contributing factor is the addition of new nephrons (Figure 3c) $(35,36)$. Amniotic fluid volume has also been used as a surrogate marker of GFR during the second half of pregnancy and is important in predicting outcomes. In the early fetal period, most of the amniotic fluid is produced by the amnion, placenta, and umbilical cord. Amniotic fluid volume increases from $\sim 25 \mathrm{ml}$ at $10 \mathrm{wk}$ of gestation to $\sim 400 \mathrm{ml}$ at $20 \mathrm{wk}$ of gestation when the fetal kidneys become the main source, although the total volume can vary substantially. By $28 \mathrm{wk}$ of gestation, the amniotic fluid volume reaches a plateau of $\sim 800 \mathrm{ml}$ until term, with a slight decline post-term (37). Severe impairment of fetal kidney function, as seen in select cases of congenital urinary tract obstruction, will manifest as oligo/anhydramnios from mid-trimester onward; however the specificity of amniotic fluid volume as a marker of fetal kidney injury in general is poor (38).

Estimates of fetal kidney integrity have also been attempted on the basis of urinary analyte levels, which can be measured in either fetal urine or in amniotic fluid. In making such estimates, the effects of normal developmental regulation of tubular maturation should be properly considered and interpreted. Fetal glomerular filtrate, and ultimately fetal urine, is modified by solute reabsorption and excretion via specific transporters and channels in the tubular epithelia. The maturation rates of these transporters and channels are differentially regulated in the specific segments of the fetal nephron, and occur over the full duration of gestation and into postnatal life (39). Therefore, for the purposes of interpretation, the concentration of a particular solute in fetal urine or amniotic fluid must be compared to normative values for that same gestational age; however, such data are, for the most part, not currently 
available. Fetal urinary sodium is the most commonly used predictor of postnatal kidney outcome. Reabsorption of filtered sodium increases in both proximal and distal tubules with progressing gestation and develops even earlier in the collecting duct, where the final regulation of sodium excretion is achieved (40). Consequently, under normal circumstances, the fractional excretion of sodium progressively decreases during
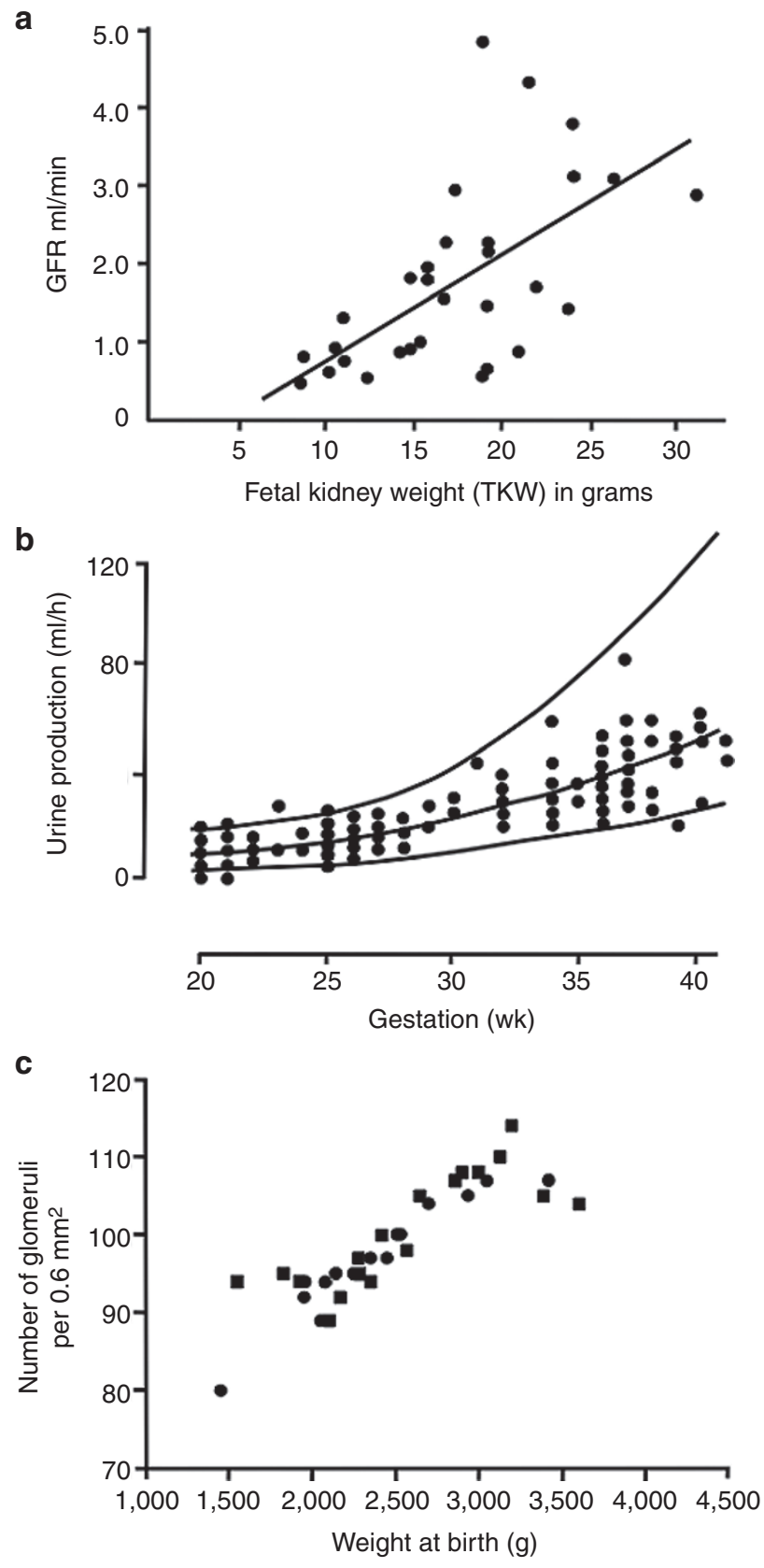

Figure 3. The relationship between fetal GFR, fetal urine production, and the number of glomeruli in the developing kidney. (a) Changes in GFR in fetal sheep in relation to total kidney weight (TKW) during gestation (GFR $\mathrm{ml} / \mathrm{min}=0.5295+0.1311($ TKW $) ; r=0.65$ ). Adapted with permission from ref. 35. (b) Hourly fetal urine production rate across gestation in human fetuses. Adapted with permission from ref. 33. (c) Relationship between birth weight and the number of glomeruli in the subcapsular cortex of human kidneys (filled squares: males; open circles: females). Reprinted and adapted with permission from ref. 36. GFR, glomerular filtration rate. gestation (Figure 4a) (41), which means that higher urinary and amniotic fluid sodium concentrations are expected in earlier stages of gestation. No normative data are available for fetal urine and amniotic fluid concentrations of potassium, phosphate, calcium, amino acids, glucose, magnesium, and organic acids. However, the somatic growth of the fetus requires positive potassium and phosphate balance (42), and this is reflected in the lower fractional excretions of these solutes in newborns as compared to children and adults $(43,44)$.With advancing gestational age, calcium, amino acid, and glucose excretion decrease, while magnesium and organic acid excretion increase, reflecting maturation of the relevant solute-specific transporters (45-47).

Several studies have investigated the usefulness of fetal urine $\beta_{2}$-microglobulin concentration as a predictor of postnatal kidney outcome. As in the case of other solutes, the capacity to reabsorb and degrade $\beta_{2}$-microglobulin increases as the proximal tubular epithelium matures with normal growth and development of the fetal kidney (48). As a result, fractional excretion of $\beta_{2}$-microglobulin decreases until a plateau is reached at $\sim 34 \mathrm{wk}$ of gestation (49) (Figure 4b). Therefore in interpreting fetal urine and amniotic fluid levels, particularly before $34 \mathrm{wk}$ of gestation, it is important to be mindful of the normal rapid changes in excretion from week to week.

The interpretation of the osmolality of fetal urine is also complicated by the fact that the fetal kidney's ability to concentrate urine (active sodium reabsorption in the loop of Henle and recycling of urea in the distal nephron) and its ability to dilute it (collecting duct cell responsiveness to antidiuretic hormone) mature with advancing gestational age (50-52). Nonetheless, early fetal urine is hypotonic as compared to urine produced later in gestation, and the fetal kidneys are able to respond to physiologic stimuli by concentrating urine; this has been demonstrated in animal studies (Figure 4c) (50).

In summary, the interpretation of analyte concentration levels in fetal urine and amniotic fluid is a complex task. The concentration levels are determined by a number of different mechanisms that are differentially regulated and develop at different times in different segments of the fetal nephron. These include the expression of segment-specific ion transporters, whose maturation is in flux during gestation. Although there is adequate knowledge available about the normal maturation of physiology in humans, normative data for the developing fetus are understandably lacking. These pitfalls have limited the clinical usefulness of these analytes.

\section{THE EFFECT OF CONGENITAL URINARY TRACT OBSTRUC- TION ON FUNCTION AND FORM}

The extent of kidney injury in congenital urinary tract obstruction depends on multiple factors such as the anatomical site of the obstruction, its severity and completeness, as well as its duration. Several animal models have defined the histopathology and pathogenesis of congenital urinary tract obstruction (53). These models have demonstrated that early obstruction leads to kidney dysplasia, characterized by cystic transformation of the developing nephron, abnormal glomerular 


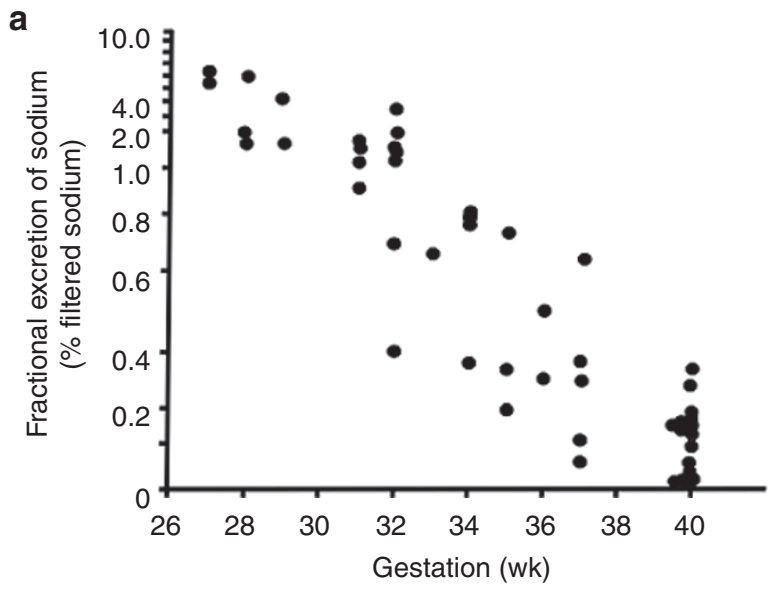

b

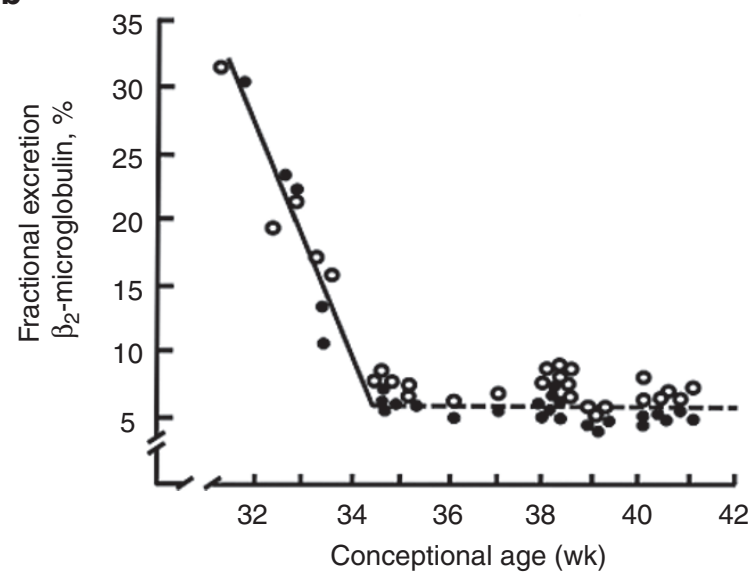

C

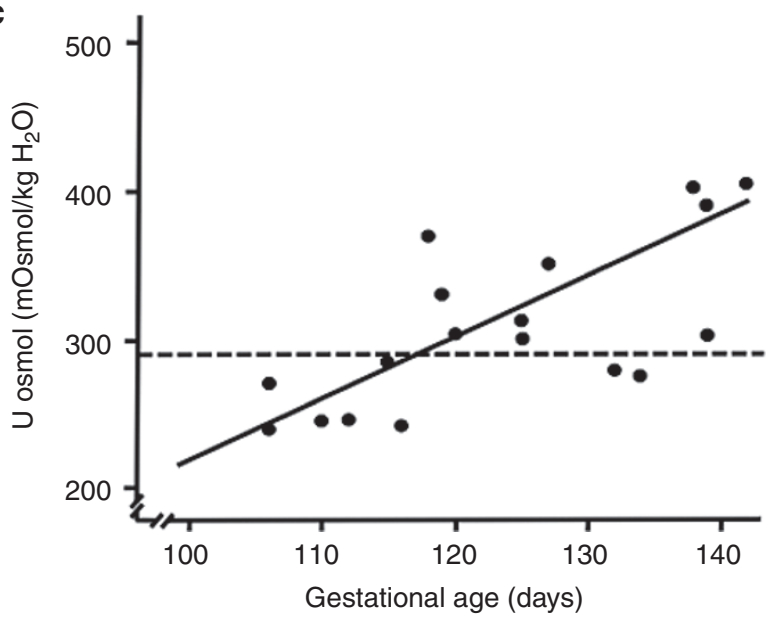

Figure 4. Decrease in fractional excretion of solutes and increase in the concentrating ability during fetal tubular maturation. (a) Fractional excretion of sodium shows changes with gestational age in the human fetus $(r=0.755, P<0.01)$. Adapted from ref. 41 with permission from John Wiley $\&$ Sons. (b) Fractional excretion of $\beta_{2}$-microglobulin in 56 healthy preterm and term infants studied on day 1 (open circles) and day 4 (filled circles). Adapted and reprinted by permission from Macmillan Publishers Ltd from ref. 49. (c) Relationship between fetal gestational age and fetal urine osmolality ( $\mathrm{U}$ osmol) during arginine vasopressin (AVP) infusion in ewes (term $145 \mathrm{~d})(y=(4.11 \times X)-190.1$, $r=0.70, P<0.001$ ) showing the relationship between fetal age and maximum $U$ osmol (solid line). The dotted line represents mean plasma osmolality (291 \pm 1.45$)$ during AVP infusion. Adapted and reprinted with permission from ref. 50 . development, and medullary hypoplasia, whereas obstruction later in gestation causes hydronephrosis without dysplastic changes (54-57). The nonhuman primate model of obstructive nephropathy (58) highlights the characteristic dysplastic changes in the obstructed kidneys, characterized by a significant decrease in glomerular number and nephron endowment, glomerular cyst formation, and significant podocyte death (53). Alterations that become evident as early as during the S-shape stage of nephron development suggest abnormal nephron induction resulting from ureteric duct obstruction and injury. Tubulointerstitial changes include dilatation of the tubules and collecting ducts, marked expansion of the renal interstitium, and a striking formation of the pericystic and periductal fibromuscular collars. Collecting-duct epithelialmesenchymal transition and cell remodeling have also been implicated in the response to tubular injury and in the development of interstitial fibrosis (59).

As in the fetal monkey model, in the obstructed human fetal kidney, the collecting-duct epithelium undergoes a phenotypic transition that is evident early in the process of obstruction, with a loss of epithelial proteins such as E-cadherin and a gain of mesenchymal proteins such as vimentin. These cells also display de novo expression of $\alpha$-smooth-muscle actin, associated with and proportional to the extent of periductal fibromuscular collar formation. Reduction in glomerular endowment and cystic changes of all nephron segments are also prominent (60) (Figure 5).

The significant tubulointerstitial changes in the obstructed fetal kidney (including epithelial phenotypic transition and fibrosis), as well as their effects on glomerular and tubular function, are not accurately reflected in current prenatal testing of affected fetuses. It is currently not possible to arrive at a close approximation of the number of glomeruli in the kidney at any stage of gestation, or to estimate accurately the extent of tubulointerstitial damage caused by obstruction. These are both fundamental prerequisites for determining postnatal and long-term kidney outcome. There is therefore a need to develop new surrogate markers of structural changes. Some of these putative biomarkers of congenital urinary tract obstruction are described in the next section.

\section{DEVELOPMENTAL KIDNEY INJURY}

Parallels can be drawn between injury of kidneys during fetal development, which we refer to here as developmental kidney injury, and injuries that occur postnatally, referred to as acute kidney injury. The morbidity and mortality associated with both types of injury remain high despite the fact that there is now a better understanding of their pathophysiology. One of the main reasons for poor outcomes in children with congenital urinary tract obstruction is the lack of methods to adequately assess the severity of kidney injury in utero. This is attributable, in large part, to the lack of early clinical markers of injury.

The ideal biomarker of developmental kidney injury would be one that can be obtained from easily accessible biological samples, is rapidly measurable using a standardized technique in a routine clinical laboratory, is highly sensitive and specific as 

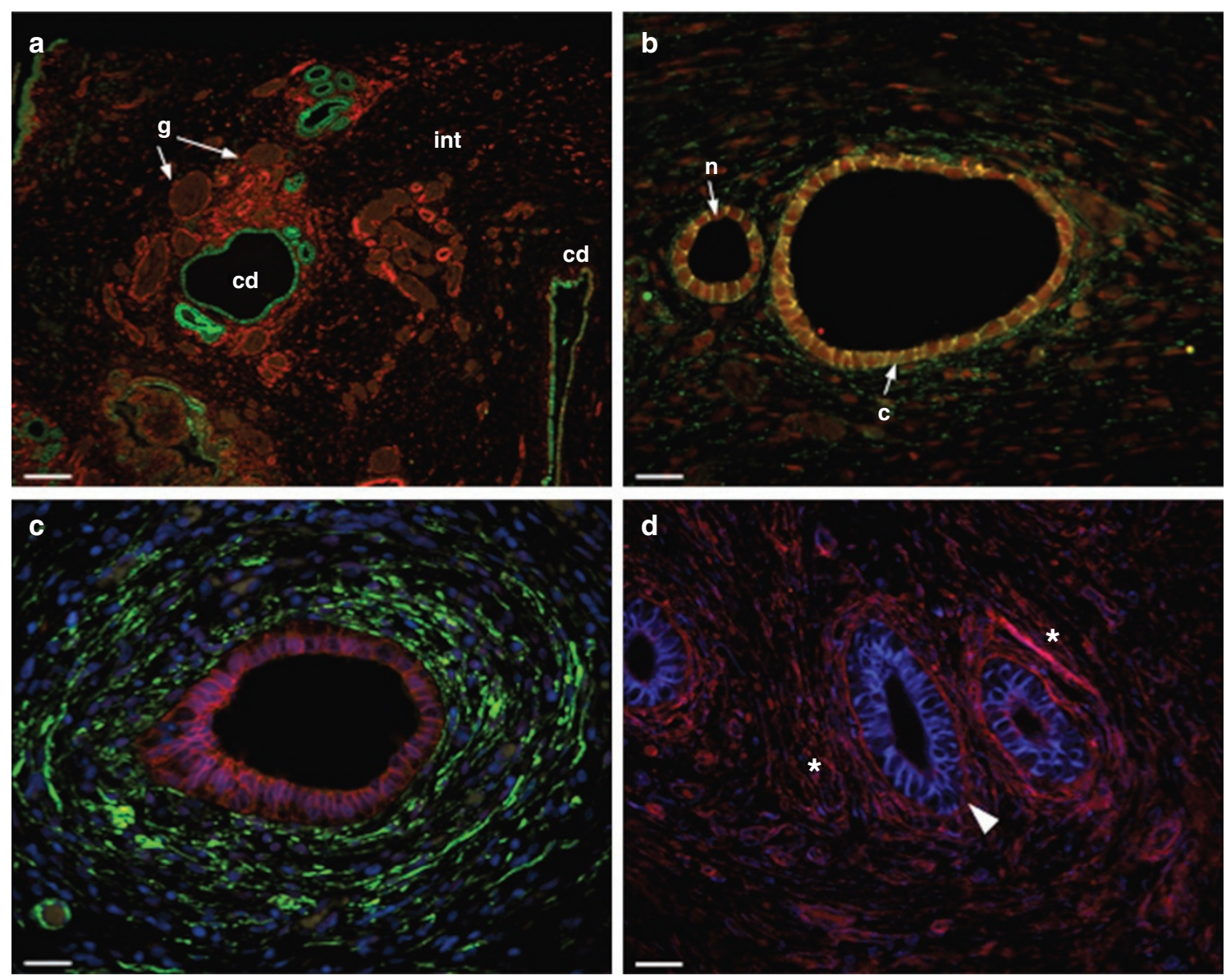

Figure 5. Kidney histopathology of human congenital urinary tract obstruction. Human kidneys were analyzed by immunohistochemistry as previously described (60). The mounted tissue sections were probed with the designated primary antibodies. The nuclei were stained with 4',6-diamidino-2phenylindole (DAPI) before being mounted on slides. The analysis was performed using epifluorescent microscopy. (a) Decreased number of glomeruli (g), dilatation of the collecting ducts (cd), and expansion of the interstitium (int) in the cortex of an obstructed 36-wk-gestation human fetal kidney (red = vimentin; green = cytokeratin) $(\mathrm{bar}=100 \mu \mathrm{m})$. (b) Collecting duct epithelium of an obstructed 36-wk gestation kidney shows the dissociation of epithelial proteins, E-cadherin (red) and $\beta$-catenin (green), from the cellular membrane, and their translocation to the nucleus ( $\mathrm{n}$ ) and cytoplasm (c), respectively. Yellow staining at the intercellular membranes represents the colocalization of E-cadherin and $\beta$-catenin (bar $=25 \mu \mathrm{m})$. (c) Formation of fibromuscular collars consisting of cells expressing a-smooth-muscle actin (green) surrounding a dilated medullary cd (red = E-cadherin; blue = DAPI) in an obstructed 36-wk-gestation kidney (bar $=25 \mu \mathrm{m}$ ). (d) Obstructed 36-wk gestation kidney shows cd epithelial cells with de novo expression of the mesenchymal protein vimentin (blue), disruption of collagen (red) in the ductal basement membrane (arrowhead), and deposition of collagen in the expanded interstitium $\left(^{*}\right)($ bar $=25 \mu \mathrm{m})$.

a predictive marker, allows stratification of risk, and correlates with postnatal clinical outcomes such as mortality, the requirement for dialysis, and morbidity (61-63). The first step in the search for such a biomarker is to understand the cellular and molecular events leading to obstructive renal dysplasia. Animal studies, such as those described earlier in this paper, are invaluable in defining processes such as tubular phenotypic changes and interstitial fibrosis in the obstructed kidneys. The key proteins involved in these events, such as transforming growth factor- $\beta$ (TGF- $\beta$ ) and the epithelial and mesenchymal cell proteins reflecting cell injury and repair, can be measured in biological fluids (Table 1). Illustrative examples of potentially useful biomarkers in congenital urinary tract obstruction include components of the renin-angiotensin system (64), inflammatory markers including monocyte chemotactic peptide-1 $(65,66)$, and adhesion molecules such as intercellular adhesion molecule-1 (67). Several studies have confirmed the utility of urinary TGF- $\beta$ levels as a marker of the severity of renal dysplasia in upper (68-70) as well as lower (71) urinary tract obstruction in the postnatal period. However, to date, no studies have investigated TGF- $\beta$ as a prenatal biomarker of renal dysplasia.

The question then is, can the putative biomarkers be measured in the most relevant biological specimens? Undoubtedly, fetal kidney tissue would be the best diagnostic source, and amniotic fluid the safest. It is also important to realize that each biological specimen can be divided into separate compartments containing different proteins. For example, a study of normal adult urine showed that $\sim 48 \%$ of total protein was contained in sediments, $49 \%$ was soluble, and the remaining $3 \%$ was in exosomes (72). Urinary exosomes, which are $40-80 \mathrm{~nm}$ vesicles of endocytic origin, are a particularly interesting source of biomarkers that might provide unique information about the degree of injury to the cells and to the tissue releasing them. The proteome of 
Table 1. Potential biomarkers of fetal obstructive nephropathy and their biological significance

\begin{tabular}{ll}
\hline Biomarker & Site of origin \\
\hline Aquaporin-2 & Collecting duct (CD) principal epithelial cell \\
Vacuolar-type H(+)-ATPase & CD-intercalated epithelial cell \\
Transforming growth factor- $\beta 1$ & $\begin{array}{l}\text { Fetal renal mesenchymal cells (interstitial } \\
\text { fibroblasts, myofibroblasts, pericytes) }\end{array}$ \\
E-cadherin & $\begin{array}{l}\text { Epithelial cells of renal tubules and CDs } \\
\beta \text {-catenin }\end{array}$ \\
Transient receptor potential vanilloid 4 & Epithelial cells of the distal fetal nephron \\
L1 cell adhesion molecule & Basolateral membrane of CD epithelial cells
\end{tabular}

Potential biological significance

Decreased excretion reflects paucity of CD principal cells, resulting in poor ability to concentrate urine

Decreased excretion reflects paucity of CD-intercalated cells, resulting in poor ability to acidify urine

Increased excretion reflects development of tissue fibrosis

Decreased excretion reflects damage to the epithelial cytoskeleton

Increased excretion reflects increased synthesis and translocation of this cytoskeletal protein into cell cytoplasm

Increased excretion might reflect increased synthesis of this molecular sensor of fluid flow

Increased excretion reflects translocation of this protein to the apical membrane of $C D$ cells and de novo expression in epithelial cells of distal tubules and the loop of Henle urinary exosomes has been characterized and includes hundreds of proteins specific to each type of epithelial cell in the lining of the urinary tract (73). Exosomes can also be recovered from amniotic fluid, a fact that has significant implications for the prenatal diagnosis and evaluation of many diseases, including congenital urinary tract obstruction (74). In the developing obstructed kidney, collecting-duct epithelial cell injury is an important component of the response to obstruction and is probably an early event. It is characterized by a decrease in expression levels of characteristic epithelial proteins and an increase in expression levels of mesenchymal cell proteins in the kidney (59), measurable in fetal urine and amniotic fluid. Results from urinary exosome proteomics suggest that these biomarkers may correlate with the degree of the tubulointerstitial damage. Specifically, candidate biomarkers of obstructive nephropathy derived from the injured collecting duct, including aquaporin 2, vacuolartype $\mathrm{H}(+)$-ATPase (V-ATPase), TGF- $\beta 1$, N-cadherin, transient receptor potential vanilloid 4 , E-cadherin, $\beta$-catenin, and $\mathrm{L} 1$ cell adhesion molecule can be readily measured in whole urine and urine exosomes (Figure 6).

Finally, new biomarkers will need to correlate with meaningful outcomes in long-term clinical studies once they are integrated into clinical practice. It is unlikely that any single analyte will have sufficient power to become a "gold standard" test for developmental kidney injury. It is more likely that several urine or amniotic fluid biomarkers in combination will provide the best accuracy and predictive value.

\section{CONCLUSIONS}

The outcomes remain poor for children with congenital urinary tract obstruction. One of the main reasons for this situation is the lack of predictive prenatal tests that can accurately identify the severity of disease. The focus on the development of new biomarkers may allow the identification of key proteins that could be measured in biological fluids, thereby reflecting the extent of developmental kidney injury. Such new biomarkers will need to be evaluated in human

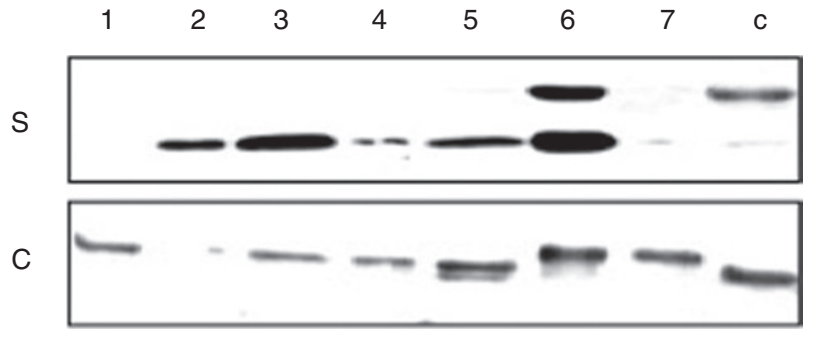

Figure 6. Western blot analysis of urine. Western blot analysis was performed on urine from children with the diagnosis of posterior urethral valves $(S)$ and from age-matched controls with no kidney disease (C). Urine was centrifuged and the supernatant concentrated before being run on an agarose gel. Blots were probed with an antibody to TGF- $\beta 1$ (Santa Cruz Biotechnology, Santa Cruz, CA), as previously described (75). The results demonstrate that it is possible to detect TGF- $\beta 1$ in urine, both in subjects with posterior urethral valves (PUVs) and in controls. Numbers at the top designate the sample lanes. The final lane (c) represents urine from a positive control. TGF- $\beta 1$, transforming growth factor- $\beta 1$.

clinical studies with multicenter collaboration in order to enroll sufficient numbers of patients, allow long-term follow-up for clinically meaningful outcomes, and ultimately provide confidence in the level of accuracy and prediction of severity of disease.

\section{STATEMENT OF FINANCIAL SUPPORT}

This study was supported, in part, by grants from the Kidney Foundation of Canada (to D.G.M.), Canadian Institutes of Health Research (to D.G.M.), BC Provincial Renal Agency (to P.T.), and the National Institutes of Health (to A.F.T.).

\section{REFERENCES}

1. Damen-Elias HA, De Jong TP, Stigter RH, Visser GH, Stoutenbeek PH. Congenital renal tract anomalies: outcome and follow-up of 402 cases detected antenatally between 1986 and 2001. Ultrasound Obstet Gynecol 2005;25:134-43.

2. Ardissino G, Daccò V, Testa $S$, et al. Epidemiology of chronic renal failure in children: data from the ItalKid project. Pediatrics 2003;111(4 Pt 1): e382-7.

3. Smith JM, Stablein DM, Munoz R, Hebert D, McDonald RA. Contributions of the Transplant Registry: The 2006 Annual Report of the North American Pediatric Renal Trials and Collaborative Studies (NAPRTCS). Pediatr Transplant 2007;11:366-73. 
4. McDonald SP, Craig JC; Australian and New Zealand Paediatric Nephrology Association. Long-term survival of children with end-stage renal disease. N Engl J Med 2004;350:2654-62.

5. Coplen DE. Prenatal intervention for hydronephrosis. J Urol 1997;157: 2270-7.

6. Holmes N, Harrison MR, Baskin LS. Fetal surgery for posterior urethral valves: long-term postnatal outcomes. Pediatrics 2001;108:E7.

7. McHugo J, Whittle M. Enlarged fetal bladders: aetiology, management and outcome. Prenat Diagn 2001;21:958-63.

8. Winyard P, Chitty L. Dysplastic and polycystic kidneys: diagnosis, associations and management. Prenat Diagn 2001;21:924-35.

9. Vanderheyden T, Kumar S, Fisk NM. Fetal renal impairment. Semin Neonatol 2003;8:279-89.

10. Anumba DO, Scott JE, Plant ND, Robson SC. Diagnosis and outcome of fetal lower urinary tract obstruction in the northern region of England. Prenat Diagn 2005;25:7-13.

11. Robyr R, Benachi A, Daikha-Dahmane F, Martinovich J, Dumez Y, Ville Y. Correlation between ultrasound and anatomical findings in fetuses with lower urinary tract obstruction in the first half of pregnancy. Ultrasound Obstet Gynecol 2005;25:478-82.

12. Martín C, Darnell A, Durán C, Bermúdez P, Mellado F, Rigol S. Magnetic resonance imaging of the intrauterine fetal genitourinary tract: normal anatomy and pathology. Abdom Imaging 2004;29:286-302.

13. Witzani L, Brugger PC, Hörmann M, Kasprian G, Csapone-Balassy C, Prayer D. Normal renal development investigated with fetal MRI. Eur J Radiol 2006;57:294-302.

14. Bunduki V, Saldanha LB, Sadek L, Miguelez J, Miyadahira S, Zugaib M. Fetal renal biopsies in obstructive uropathy: feasibility and clinical correlations-preliminary results. Prenat Diagn 1998;18:101-9.

15. Nava S, Bocconi L, Zuliani G, Kustermann A, Nicolini U. Aspects of fetal physiology from 18 to 37 weeks' gestation as assessed by blood sampling. Obstet Gynecol 1996;87:975-80.

16. Berry SM, Lecolier B, Smith RS, et al. Predictive value of fetal serum beta 2-microglobulin for neonatal renal function. Lancet 1995;345:1277-8.

17. Cobet G, Gummelt T, Bollmann R, Tennstedt C, Brux B. Assessment of serum levels of alpha-1-microglobulin, beta-2-microglobulin, and retinol binding protein in the fetal blood. A method for prenatal evaluation of renal function. Prenat Diagn 1996;16:299-305.

18. Tassis BM, Trespidi L, Tirelli AS, Pace E, Boschetto C, Nicolini U. Serum beta 2-microglobulin in fetuses with urinary tract anomalies. Am J Obstet Gynecol 1997;176(1 Pt 1):54-7.

19. Nicolini U, Spelzini F. Invasive assessment of fetal renal abnormalities: urinalysis, fetal blood sampling and biopsy. Prenat Diagn 2001;21:964-9.

20. Crombleholme TM, Harrison MR, Golbus MS, et al. Fetal intervention in obstructive uropathy: prognostic indicators and efficacy of intervention. Am J Obstet Gynecol 1990;162:1239-44.

21. Lipitz S, Ryan G, Samuell C, et al. Fetal urine analysis for the assessment of renal function in obstructive uropathy. Am J Obstet Gynecol 1993;168 (1 Pt 1):174-9.

22. Glick PL, Harrison MR, Golbus MS, et al. Management of the fetus with congenital hydronephrosis II: Prognostic criteria and selection for treatment. J Pediatr Surg 1985;20:376-87.

23. Morris RK, Quinlan-Jones E, Kilby MD, Khan KS. Systematic review of accuracy of fetal urine analysis to predict poor postnatal renal function in cases of congenital urinary tract obstruction. Prenat Diagn 2007;27:900-11.

24. Agarwal SK, Fisk NM. In utero therapy for lower urinary tract obstruction. Prenat Diagn 2001;21:970-6.

25. Biard JM, Johnson MP, Carr MC, et al. Long-term outcomes in children treated by prenatal vesicoamniotic shunting for lower urinary tract obstruction. Obstet Gynecol 2005;106:503-8.

26. Gersh I. The correlation of structure and function in the developing mesonephros and metanephros. Contrib Embryol 1937;153:35-58.

27. Arant BS Jr. Developmental patterns of renal functional maturation compared in the human neonate. J Pediatr 1978;92:705-12.

28. Arant BS Jr. Neonatal adjustments to extrauterine life. In: Edelmann CM, ed. Pediatric Kidney Disease (vol 1). Boston, MA: Little, Brown and Co, 1992:1021.
29. Potter EL, Thierstein ST. Glomerular development in the kidney as an index of fetal maturity. J Pediatr 1943;22:195.

30. Hill KJ, Lumbers ER. Renal function in adult and fetal sheep. J Dev Physiol 1988;10:149-59.

31. Veille JC, Hanson RA, Tatum K, Kelley K. Quantitative assessment of human fetal renal blood flow. Am J Obstet Gynecol 1993;169:1399-402.

32. Satlin LM, Woda CB, Schwartz GJ. Development of function in the metanephric kidney. In: Vize PD, Woolf AS, Bard JBL, eds. The Kidney: From Normal Development to Congenital Disease, 1st edn. London, UK: Academic Press, 2003:267-325.

33. Rabinowitz R, Peters MT, Vyas S, Campbell S, Nicolaides KH. Measurement of fetal urine production in normal pregnancy by real-time ultrasonography. Am J Obstet Gynecol 1989;161:1264-6.

34. Hedriana HL. Ultrasound measurement of fetal urine flow. Clin Obstet Gynecol 1997;40:337-51.

35. Robillard JE, Kulvinskas C, Sessions C, Burmeister L, Smith FG Jr. Maturational changes in the fetal glomerular filtration rate. Am J Obstet Gynecol 1975;122:601-6.

36. Mañalich R, Reyes L, Herrera M, Melendi C, Fundora I. Relationship between weight at birth and the number and size of renal glomeruli in humans: a histomorphometric study. Kidney Int 2000;58:770-3.

37. Underwood MA, Gilbert WM, Sherman MP. Amniotic fluid: not just fetal urine anymore. J Perinatol 2005;25:341-8.

38. Suresh S, Jindal S, Duvuru P, Lata S, Sadiya N. Fetal obstructive uropathy: impact of renal histopathological changes on prenatal interventions. Prenat Diagn 2011;31:675-7.

39. Jones DP, Chesney RW. Development of tubular function. Clin Perinatol 1992;19:33-57.

40. Aperia A, Elinder G. Distal tubular sodium reabsorption in the developing rat kidney. Am J Physiol 1981;240:F487-91.

41. Siegel SR, Oh W. Renal function as a marker of human fetal maturation. Acta Paediatr Scand 1976;65:481-5.

42. Satlin LM. Maturation of renal potassium transport. Pediatr Nephrol 1991;5:260-9.

43. Giebisch G. Renal potassium transport: mechanisms and regulation. Am J Physiol 1998;274(5 Pt 2):F817-33.

44. Kaskel FJ, Kumar AM, Feld LG, Spitzer A. Renal reabsorption of phosphate during development: tubular events. Pediatr Nephrol 1988;2:129-34.

45. Wittner M, Desfleurs E, Pajaud S, et al. Calcium and magnesium transport in the cortical thick ascending limb of Henle's loop: influence of age and gender. Pflugers Arch 1997;434:451-6.

46. Brodehl J, Gellissen K. Endogenous renal transport of free amino acids in infancy and childhood. Pediatrics 1968;42:395-404.

47. Robillard JE, Sessions C, Kennedy RL, Smith FG Jr. Maturation of the glucose transport process by the fetal kidney. Pediatr Res 1978;12:680-4.

48. Schaeverbeke J, Cheignon M. Differentiation of glomerular filter and tubular reabsorption apparatus during foetal development of the rat kidney. J Embryol Exp Morphol 1980;58:157-75.

49. Assadi FK, John EG, Justice P, Fornell L. Beta 2-microglobulin clearance in neonates: index of tubular maturation. Kidney Int 1985;28:153-7.

50. Robillard JE, Weitzman RE. Developmental aspects of the fetal renal response to exogenous arginine vasopressin. Am J Physiol 1980;238:F407-14.

51. Calcagno PL, Rubin MI, Weintraub DH. Studies on the renal concentrating and diluting mechanisms in the premature infant. J Clin Invest 1954;33:91-6.

52. Rane S, Aperia A, Eneroth P, Lundin S. Development of urinary concentrating capacity in weaning rats. Pediatr Res 1985;19:472-5.

53. Matsell DG, Tarantal AF. Experimental models of fetal obstructive nephropathy. Pediatr Nephrol 2002;17:470-6.

54. Beck AD. The effect of intra-uterine urinary obstruction upon the development of the fetal kidney. J Urol 1971;105:784-9.

55. Harrison MR, Nakayama DK, Noall R, de Lorimier AA. Correction of congenital hydronephrosis in utero II. Decompression reverses the effects of obstruction on the fetal lung and urinary tract. J Pediatr Surg 1982;17:965-74.

56. Peters CA, Carr MC, Lais A, Retik AB, Mandell J. The response of the fetal kidney to obstruction. J Urol 1992;148(2 Pt 2):503-9. 
57. Josephson S, Robertson B, Rodensjö M. Effects of experimental obstructive hydronephrosis on the immature nephrons in newborn rats. Urol Int 1989;44:61-5.

58. Tarantal AF, Han VK, Cochrum KC, Mok A, daSilva M, Matsell DG. Fetal rhesus monkey model of obstructive renal dysplasia. Kidney Int 2001;59:446-56.

59. Butt MJ, Tarantal AF, Jimenez DF, Matsell DG. Collecting duct epithelial-mesenchymal transition in fetal urinary tract obstruction. Kidney Int 2007;72:936-44.

60. Trnka P, Hiatt MJ, Ivanova L, Tarantal AF, Matsell DG. Phenotypic transition of the collecting duct epithelium in congenital urinary tract obstruction. J Biomed Biotechnol 2010;2010:696034.

61. Nguyen MT, Devarajan P. Biomarkers for the early detection of acute kidney injury. Pediatr Nephrol 2008;23:2151-7.

62. Zhou H, Hewitt SM, Yuen PS, Star RA. Acute Kidney Injury Biomarkers - Needs, Present Status, and Future Promise. Nephrol Self Assess Program 2006;5:63-71.

63. Han WK, Bonventre JV. Biologic markers for the early detection of acute kidney injury. Curr Opin Crit Care 2004;10:476-82.

64. Fern RJ, Yesko CM, Thornhill BA, Kim HS, Smithies O, Chevalier RL. Reduced angiotensinogen expression attenuates renal interstitial fibrosis in obstructive nephropathy in mice. J Clin Invest 1999;103:39-46.

65. Chevalier RL. Obstructive nephropathy: towards biomarker discovery and gene therapy. Nat Clin Pract Nephrol 2006;2:157-68.

66. Grandaliano G, Gesualdo L, Bartoli F, et al. MCP-1 and EGF renal expression and urine excretion in human congenital obstructive nephropathy. Kidney Int 2000;58:182-92.
67. Shappell SB, Mendoza LH, Gurpinar T, Smith CW, Suki WN, Truong LD. Expression of adhesion molecules in kidney with experimental chronic obstructive uropathy: the pathogenic role of ICAM-1 and VCAM-1. Nephron 2000;85:156-66.

68. Furness PD 3rd, Maizels M, Han SW, Cohn RA, Cheng EY. Elevated bladder urine concentration of transforming growth factor-betal correlates with upper urinary tract obstruction in children. J Urol 1999;162(3 Pt 2): 1033-6.

69. El-Sherbiny MT, Mousa OM, Shokeir AA, Ghoneim MA. Role of urinary transforming growth factor-betal concentration in the diagnosis of upper urinary tract obstruction in children. J Urol 2002;168(4 Pt 2):1798-800.

70. Palmer LS, Maizels M, Kaplan WE, Firlit CF, Cheng EY. Urine levels of transforming growth factor-beta 1 in children with ureteropelvic junction obstruction. Urology 1997;50:769-73.

71. MacRae Dell K, Hoffman BB, Leonard MB, Ziyadeh FN, Schulman SL. Increased urinary transforming growth factor-beta(1) excretion in children with posterior urethral valves. Urology 2000;56:311-4.

72. Zhou H, Yuen PS, Pisitkun T, et al. Collection, storage, preservation, and normalization of human urinary exosomes for biomarker discovery. Kidney Int 2006;69:1471-6.

73. Pisitkun T, Shen RF, Knepper MA. Identification and proteomic profiling of exosomes in human urine. Proc Natl Acad Sci USA 2004;101:13368-73.

74. Keller S, Rupp C, Stoeck A, et al. CD24 is a marker of exosomes secreted into urine and amniotic fluid. Kidney Int 2007;72:1095-102.

75. Ivanova L, Butt MJ, Matsell DG. Mesenchymal transition in kidney collecting duct epithelial cells. Am J Physiol Renal Physiol 2008;294: F1238-48. 